Article (refereed)

Whitaker, J.; Chaplow, J.S.; Potter, E.; Scott, W.A.;

Hopkin, S.; Harman, M.; Sims, I.; Sorokin, N.. 2009 The

comparative toxicity to soil invertebrates of natural chemicals and their synthetic analogues. Chemosphere, 76 (3). 345-352. 10.1016/j.chemosphere.2009.03.060

Copyright @ 2009 Elsevier Ltd

This version available at http://nora.nerc.ac.uk/6986/

NERC has developed NORA to enable users to access research outputs wholly or partially funded by NERC. Copyright and other rights for material on this site are retained by the authors and/or other rights owners. Users should read the terms and conditions of use of this material at http://nora.nerc.ac.uk/policies.html\#access

This document is the author's final manuscript version of the journal article, incorporating any revisions agreed during the peer review process. Some differences between this and the publisher's version remain. You are advised to consult the publisher's version if you wish to cite from this article.

http://www.elsevier.com/ 


\section{The comparative toxicity to soil invertebrates of natural chemicals and their synthetic analogues}

J. Whitaker ${ }^{a^{*}}$, J.S. Chaplow ${ }^{\text {a }}$, E. Potter ${ }^{\text {a }}$, W.A. Scott ${ }^{\mathrm{a}}$, S. Hopkin ${ }^{\mathrm{b}}$, M. Harman ${ }^{\mathrm{c}}$, I. Sims ${ }^{\mathrm{d}}$ and N. Sorokin

(a) Centre for Ecology \& Hydrology, Lancaster Environment Centre, Library Avenue, Bailrigg, Lancaster, LA1 4AP, UK.

(b) Division of Zoology, School of Animal \& Microbial Sciences, University of Reading, Reading, RG6 6AJ, UK.

(c) WRc PLC, Blagrove Park, Swindon, SN5 8YF, UK.

(d) Syngenta, Jealott's Hill International Research Centre, Bracknell, RG42 6EY, UK.

(e) Reckitt Benckiser, Dansom Lane, Hull, HU8 7DS, UK.

*Corresponding author. Tel.: +44 1524 595888; fax +44 152461536.

E-mail address: jhart@ceh.ac.uk 


\section{Abstract}

2 The introduction of REACH (Registration, Evaluation and Authorisation of Chemicals),

3 requires companies to register and risk assess all substances produced or imported in volumes

4 of $>1$ tonne per year. Extrapolation methods which use existing data for estimating the effects

5 of chemicals are attractive to industry, and comparative data are therefore increasingly in

6 demand. Data on natural toxic chemicals could be used for extrapolation methods such as

7 read-across. To test this hypothesis, the toxicity of natural chemicals and their synthetic

8 analogues were compared using standardised toxicity tests. Two chemical pairs: the

9 napthoquinones, juglone (natural) and 1,4-naphthoquinone (synthetic); and anthraquinones,

10 emodin (natural) and quinizarin (synthetic)) were chosen, and their comparative effects on the

11 survival and reproduction of collembolans, earthworms, enchytraeids and predatory mites

12 were assessed. Differences in sensitivity between the species were observed with the 13 predatory mite (Hypoaspis aculeifer) showing the least sensitivity. Within the chemical pairs,

14 toxicity to lethal and sub-lethal endpoints was very similar for the four invertebrate species.

15 The exception was earthworm reproduction, which showed differential sensitivity to the

16 chemicals in both naphthoquinone and anthraquinone pairs. Differences in toxicity identified

17 in the present study may be related to degree of exposure and/or subtle differences in the

18 mode of toxic action for the chemicals and species tested. It may be possible to predict

19 differences by identifying functional groups which infer increased or decreased toxicity in one

20 or other chemical. The development of such techniques would enable the use of read-across

21 from natural to synthetic chemicals for a wider group of compounds.

24 Keywords: anthraquinone, napthoquinone, ecotoxicity, risk assessment 


\section{1. Introduction}

26 It is estimated that of the 100,000 chemical substances registered in the European market

27 before 1981, one third still lack information on their intrinsic properties and only 140 have

28 been singled out for risk assessment (DEFRA, 2006). The introduction of REACH

29 (Registration, Evaluation and Authorisation of Chemicals) in 2008, requires companies to

30 register and risk assess all substances produced or imported in volumes of $>1$ tonne per year

31 (30,000 substances), however, the available data are often insufficient to assess the range of

32 chemicals currently in use. Integral to REACH is a requirement to reduce the need for further

33 toxicity testing. Consequently, methods which use existing data for estimating the effects of

34 substances are attractive to industry: for example Quantitative Structure-Activity

35 Relationships (QSARs), and read-across. Such approaches rely on the principle that the

36 chemical structure of a substance determines its behaviour and effects.

38 Data on natural plant toxins could potentially be used for read-across type methods. Plants

39 produce and release into the environment an enormous range of chemicals including:

40 phenolics, terpenoids and alkaloids (38,000 characterised) (Langenheim, 1994; Harborne and

41 Baxter, 1996). Data on the fate and effects of these natural toxins could provide insight into

42 the potential impacts of structurally similar synthetic chemicals. Previous work, using

43 literature data, has shown strong similarities in the fate and effects of natural plant toxins and

44 synthetic analogues in soils (Sorokin, 2007; Sorokin and Whitaker 2008). In order to confirm

45 the suitability of using data on natural toxins for read-across methods, we made experimental

46 comparisons of the toxicity of two chemical pairs on the survival and reproduction of four

47 groups of soil invertebrates: earthworms; collembolans; enchytraeids; and predatory mites

48 using standard ecotoxicity tests. In comparing the toxicity to four representative groups of soil 
49 invertebrates we aimed to determine whether read-across could be used to assess the toxicity

50 of chemicals in soil ecosystems.

52 Natural chemicals produced by plants were chosen with properties relevant to the risk 53 assessment of synthetic chemicals i.e. presence in soil, persistence in soil and potential 54 toxicity to a range of soil organisms. In addition, natural chemicals were chosen so that 55 suitable synthetic analogues could be selected, representative of chemicals for which risk 56 assessments may need to be carried out. Based on these criteria two natural chemicals were 57 chosen (Table 1). Juglone (5-hydroxy-1,4-naphthoquinone), a naphthoquinone identified in 58 the walnut genus Juglans (Willis, 2000), and emodin (1,3,8-trihydroxy-659 methylanthraquinone), an anthraquinone identified in at least 94 plant species (Izhaki, 2002).

60 Synthetic analogues for each chemical were then chosen: for juglone, 1,4-naphthoquinone;

61 and for emodin, 1,4-dihydroxyanthraquinone (known as quinizarin) (ECB, 2004). Both

62 synthetic chemicals have wide industrial uses including chemical synthesis, textile processing,

63 biocide manufacture and in the colouring industries (IUCLID, 2000).

64

\section{2. Material and Methods}

66 Standardized methods have been developed for assessing chemical toxicity to soil

67 invertebrates. To address the objectives of this study we chose the collembolan reproduction

68 test (ISO, 1999); the earthworm reproduction test (OECD, 2004a); the enchytraeid

69 reproduction test $(\mathrm{OECD}, 2004 \mathrm{~b})$; and a modified predatory mite reproduction test (Hamers

70 and Krogh, 1997). Since the completion of these experiments, OECD have published

71 Guideline 226 for testing chemical effects on reproduction of predatory mites (OECD, 2008),

72 however our method differs from this guideline in a number of ways. In addition, a number 
73 of minor deviations from published protocols were necessary in order to complete this wide

74 range of tests, all deviations are detailed in the methods below.

75

$76 \quad 2.1$ Test species

77 All cultures were kept at $20 \pm 1{ }^{\circ} \mathrm{C}$ with a $16: 8 \mathrm{~h}$ photo-period prior to testing. Folsomia 78 candida (Collembola: Isotomidae) obtained from Reading University, were cultured on a 79 moist substrate of plaster of Paris/charcoal (8:1) and fed dried bakers yeast. Synchronised 80 cohorts for testing were obtained by transferring several hundred adults to clean culture 81 vessels for 2-3 days. Adults were then removed to allow eggs laid by the females to hatch

82 Eisenia fetida (Lumbricidae: Oligochaeta) were purchased from Aquaculture Supplies, UK.

83 They were kept in commercial culture soil at $\sim 35 \%$ soil moisture content and were fed dried

84 and ground rabbit manure as required. Cultures of Enchytraeus albidus (Enchytraeidae:

85 Oligochaeta) were also purchased from Aquaculture Supplies, UK in commercial culture

86 medium and fed ground rolled oats as required. Cultures of Hypoaspis aculeifer Canestrini

87 (Gamasida: Laelapidae) were purchased from Biological Crop Protection Ltd., UK. They

88 were cultured under the same conditions as F. candida, and were fed with $F$. candida or

89 Folsomia fimetaria L. (Collembola: Isotomidae) as required. Synchronised cultures for testing

90 were obtained by transferring several hundred adults to clean culture vessels at a ratio of 10

91 females: 5 males for 3 days. Adults were then removed to allow eggs laid by the females to 92 hatch.

93

942.2 Chemicals

95 Juglone (5-hydroxy-1,4-naphthoquinone), 1,4-naphthoquinone, quinizarin (1,496 dihydroxyanthraquinone), acetone and dichloromethane (DCM) were obtained from Sigma- 
97 Aldrich, UK. Emodin (1,3,8-trihydroxy-6-methylanthraquinone) was obtained from

98 Xtrasynthase France. All reagents were of $95 \%$ purity or greater.

99

100

\subsection{Test soil and treatments}

101 All tests were conducted in standard OECD artificial soil (pH $6 \pm 0.5$ (pH-KCl) (OECD, 102 2004a). Soil moisture content was maintained at 35\% maximum water holding capacity 103 (WHC, d. wt.) for tests with E. fetida and F. candida and $50 \%$ maximum WHC for tests with 104 E. albidus and H. aculeifer. Range-finding mortality tests were conducted with each chemical 105 and each test species to determine a suitable concentration range for the reproduction tests. 106 Eight concentrations with a factor of two spacing were used in each test, with three replicates 107 per test concentration. Concentrations ranged from 8 to $1024 \mathrm{mg} \mathrm{kg}^{-1} \mathrm{~d}$. wt for all tests, 108 except the enchytraeid and predatory mite tests with the napthoquinones where the range was 1094 to $512 \mathrm{mg} \mathrm{kg}^{-1}$ (range adjusted due to range-finding test results). These concentrations were 110 nominal as we did not analyse the treated soil to determine the actual concentrations due to 111 the complexity of analysing these compounds. In addition controls and solvent controls were 112 prepared with either three (mites), six (collembola and earthworm) or eight (enchytraeid) 113 replicates.

(a) Soil treatments for collembola, earthworm and predatory mite tests

116 Test substances were dissolved in a 50:50 (v:v) mixture of DCM and acetone to produce stock 117 solutions corresponding to the highest test dosage. Test soils were prepared by mixing the 118 appropriate amount of stock solution into the soil. Solvent controls (50:50, acetone: DCM) 119 were prepared in the same manner using the highest volume of solvent used to generate the 120 test soils (50 ml kg${ }^{-1}$ or $26.5 \mathrm{ml} \mathrm{kg}^{-1}$ for H. aculeifer). After mixing, the solvent was 
evaporated for $24 \mathrm{~h}$ after which the water content of the soil was adjusted to $35 \%$ maximum WHC (50\% for H. aculeifer).

(b) Soil treatments for enchytraeid test

125 Test substances were dissolved in acetone in a stock solution corresponding to the highest test 126 dosage. For this test the treated soil was prepared individually in each test vessel. Sand (1 g) 127 was placed in each screw top glass jar ( 200 $\mathrm{ml}$ vol.), appropriate volumes of the test 128 solutions were then added to the sand and allowed to evaporate for $24 \mathrm{~h}$. In addition, to the

129 test soils, controls, and solvent controls (acetone) were prepared in the same manner using the 130 highest volume of solvent used to generate the test soils (500 $\mathrm{ml} \mathrm{kg}^{-1}$ acetone). Half131 moistened soil (20 g d. wt) was then added to each jar and mixed thoroughly. After mixing, 132 the moisture content of the soils was adjusted to $50 \%$ maximum WHC.

135 (a) Collembola reproduction test

136 Tests were carried out in $100 \mathrm{ml}$ glass jars filled with $30 \mathrm{~g}$ (w. wt.) of test soil. Fifteen, 10$13712 \mathrm{~d}$ old F. candida were placed into each vessel with $2 \mathrm{mg}$ of bakers yeast. Test vessels were 138 maintained at $20 \pm 1{ }^{\circ} \mathrm{C}$ with a $16: 8 \mathrm{~h}$ photo-period and moisture levels were adjusted twice 139 weekly. After $14 \mathrm{~d}, 2 \mathrm{mg}$ of bakers yeast was added to each vessel and after $28 \mathrm{~d}$ the test was 140 terminated. Jars were flooded with deionised water, stirred, and the contents transferred to $141200 \mathrm{ml}$ glass containers. A small quantity $(\sim 2 \mathrm{ml})$ of black Indian ink was added to each jar to 142 increase the definition of the collembolans for counting. Digital photographs were taken and 143 the number of surviving adults and juveniles quantified by manual counting and marking of 144 photographs. 
147 Flat-bottomed glass jars (1 L) were filled with $800 \mathrm{~g}$ (w. wt.) of test soil and eight adult

148 E. fetida (400 $\pm 100 \mathrm{mg})$ with a pronounced clitellum were placed into each vessel. After

$14924 \mathrm{~h}, 0.5 \mathrm{~g}$ of dried, ground rabbit manure was added to each vessel and weekly thereafter.

150 Vessels were sealed with netting and elastic bands, maintained at $20 \pm 1{ }^{\circ} \mathrm{C}$ with a $16: 8 \mathrm{~h}$

151 photo-period and moisture levels adjusted three times per week. After $28 \mathrm{~d}$, adult earthworms

152 were dry sieved from the test vessels using a $10 \mathrm{~mm}$ sieve, and the number of surviving adults

153 was recorded. The sieved soils were then returned to the vessels with additional food $(0.5 \mathrm{~g})$

154 and left for a further $28 \mathrm{~d}$. After this time each vessel was wet sieved using 1 and $0.5 \mathrm{~mm}$

155 sieves and the number of juvenile worms counted.

156

\section{(c) Enchytraeid reproduction test}

158 Prior to the test, approximately 1000 adult E. albidus (approx $1 \mathrm{~cm}$ long with eggs in the 159 clitellum region) were acclimated in OECD artificial soil for $24 \mathrm{~h}$. Test soils were prepared in 160 each test vessel (20 g d. wt.) as described above. Autoclaved, ground rolled oats (50 mg) 161 were mixed into the soil in each vessel and 10 adult E. albidus added. Test vessels were then 162 covered with parafilm, maintained at $20 \pm 1{ }^{\circ} \mathrm{C}$ with a $16: 8 \mathrm{~h}$ photo-period and moisture levels 163 adjusted weekly. On days 7, 14, 21 and 35, $25 \mathrm{mg}$ of rolled oats were added to each vessel.

164 On day 21, all adult worms were removed and counted and any changes in adult behaviour 165 were observed. After $42 \mathrm{~d}$ the test was terminated newly hatched worms stained using the 166 Bengal staining method (OECD, 2004b) and counted under a microscope (10x mag.).

169 This method was based on the method of Hamers and Krogh (1997) which has since been 
171 high, $6 \mathrm{~cm}$ diameter) with a $1 \mathrm{~mm}$ mesh base were filled with $60 \mathrm{~g}$ (w. wt.) of test soil. On day

1720,100 collembolan prey (16-19 d old F. fimetaria) were introduced to each test vessel and

173 allowed to disperse for $1 \mathrm{~h}$. Ten female and 5 male $H$. aculeifer (16-19 d old) were allocated 174 to each test vessel and the vessels were then covered with parafilm, maintained at $20 \pm 1{ }^{\circ} \mathrm{C}$

175 with a 12:12 h photo-period and moisture levels adjusted weekly. Collembolan prey were fed

176 with $15 \mathrm{mg}$ bakers yeast every 7 days and mites were fed young $\sim 20 \mathrm{~d}$ old $F$. fimetaria twice

177 per week. On day 21 the test was terminated and test vessels transferred to high gradient

178 extractors for $48 \mathrm{~h}$ (25 watt bulb). Extracted animals were collected in universal tubes with a

179 moist plaster of paris/charcoal base, frozen at $-18{ }^{\circ} \mathrm{C}$ and counted within $48 \mathrm{~h}$.

\subsection{Statistical analysis}

182 Average adult survival, reproduction (number of juveniles) and juvenile/adult ratios were 183 calculated at each treatment concentration. Generalised linear models were used to model 184 each of these variables as a function of concentration (SAS 9.1). For adult survival a logit

185 link function was used, since the counts had both an upper and lower bound, with a binomial 186 error. A log link transformation was used for the juveniles and juvenile/adult ratios, as these

187 were both counts with no upper limit, with a Poisson error. In all cases allowance was made 188 for over-dispersion. Initially models were fitted to the control data to determine whether there 189 was a significant effect of the solvent carrier, on adult survival or reproduction. Effect 190 estimates $\left(\mathrm{LC}_{50}\right.$, effective concentration causing a $50 \%$ reduction in survival; $\mathrm{EC}_{50}$, effective 191 concentration causing a $50 \%$ reduction in reproduction) were calculated as functions of 192 model parameters and their standard errors (SE). Likelihood ratio tests were used to compare 193 dose response effects across chemicals (SAS v. 9.1).

\section{Results}


197 Average adult survival in the controls (non-solvent and solvent) for collembola, earthworms 198 and enchytraeids was greater than $95 \%$ (data not shown). Adult control survival was lower 199 for the predatory mite test at $73 \%$ and $60 \%$ for non-solvent and solvent controls respectively, 200 which is below the $20 \%$ mortality limit in the OECD guideline published recently. This may 201 be due to difficulties with the extraction of these organisms from soil. The number of adults 202 surviving was not significantly affected by the type of control treatment in all experiments 203 ( $\mathrm{p}>0.05$, data not shown), and the number of enchytraeid and predatory mite juveniles were 204 also not significantly different between the control and solvent control treatments $(\mathrm{p}>0.05)$. 205 In contrast, the number of juvenile collembola and earthworms were significantly different for 206 the two control types, with higher numbers of juveniles in the solvent control compared with 207 the ordinary control ( $\mathrm{p}<0.001$, data not shown). For F. candida, there was an average of 678 $208( \pm 73)($ mean $( \pm$ SE) $)$ juveniles in the controls and $1273( \pm 107)$ in the solvent controls, whilst 209 for E. fetida, values were $31( \pm 3)$ and $63( \pm 5)$ juveniles for the control and solvent controls 210 respectively. This shows that the presence of the solvent stimulated reproduction in these two 211 species. Non-solvent controls were therefore excluded from the statistical analysis of juvenile 212 data for these two species. For consistency they were also excluded from analysis of adult 213 survival. Non-solvent controls and solvent controls were pooled for analysis of the 214 enchytraeid and predatory mite data as no solvent effect was observed for these species.

\subsection{Toxicity of naphthoquinones}

217 Exposure to juglone and 1,4-naphthoquinone significantly reduced survival and reproduction 218 of F. candida, E. fetida, and E. albidus, with clear dose-response relationships observed (Fig. 219 1a-c, Table 2). The exception was the predatory mite H. aculeifer which had lower sensitivity 220 to the two chemicals compared to the other species, with no significant effect of either 
221 chemical on reproduction (Fig. 1d, Table 2). The juvenile/adult ratio was not significantly

222 affected by juglone for the four species tested, indicating that where adults survived they

223 reproduced at the same rate, irrespective of exposure concentration (Table 2). In contrast,

224 when exposed to 1,4-naphthoquinone, adult reproduction rates (juvenile:adult ratio) of all

225 species except $F$. candida decreased significantly with increasing concentration (Table 2).

226

227 When comparing the relative effects of the natural (juglone) and synthetic (1,4-

228 naphthoquinone) naphthoquinones on mortality and reproduction, we found that results were

229 generally consistent across the four species and two endpoints, with little significant

230 difference in effect of the two chemicals (Table 2). The exceptions to this were earthworm

231 reproduction, which was significantly more sensitive to 1,4-naphthoquinone compared to

232 juglone $(\mathrm{p}<0.0001)$ and collembolan survival which was also more sensitive to 1,4-

233 naphthoquinone (Table 2). These differences are reflected in the $\mathrm{EC}_{50}$ values for earthworm

234 reproduction of $239( \pm 55)$ and $99( \pm 24) \mathrm{mg} \mathrm{kg}^{-1}$ and the $\mathrm{LC}_{50}$ values for collembolan

235 survival of $124( \pm 34)$ and $75( \pm 15) \mathrm{mg} \mathrm{kg}^{-1}$ for juglone and 1,4-naphthoquinone respectively,

236 illustrating the higher toxicity of 1,4-naphthoquinone in these instances (Table 2).

237

238 A comparison of the $\mathrm{LC}_{50}$ and $\mathrm{EC}_{50}$ values was conducted to examine the relative sensitivity

239 of the two endpoints tested. This comparison revealed that the relative sensitivity of survival

240 and reproduction was consistent within the species tested but varied interspecifically (Table

241 2). For F. candida, reproduction was less sensitive than survival for both napthoquinones,

242 whilst for E. fetida and E. albidus the opposite was true.

243

2443.3 Toxicity of anthraquinones 
245 Overall, the anthraquinones were considerably less toxic to the four species than the

246 naphthoquinones. Despite this, some interspecific variation in sensitivity of both mortality and

247 reproduction was revealed in the results. The only significant finding was that emodin 248 significantly inhibited reproduction of E. fetida, with an $\mathrm{EC}_{50}$ value of $182( \pm 44) \mathrm{mg} \mathrm{kg}^{-1}$

249 (Table 2, Fig. 2b). In contrast adult E. fetida were insensitive to anthraquinone exposure in 250 terms of survival. This finding was reflected in the significant effect of emodin on the 251 juvenile/adult ratio. Of the four species tested, E. albidus was the least sensitive to the two 252 anthraquinones, with no significant effect on survival or reproduction (the apparent significant

253 positive dose response relationship for adult survival under exposure to emodin is an artefact 254 of the very small variation in survival rates for this species) (Table 2, Fig. 2c). Results from 255 the predatory mite tests showed no significant effect of either chemical on survival or 256 reproduction. Examination of the plotted data (Fig. 2d) shows very similar response to the 257 two chemicals, however, the variability of the dataset makes it difficult to draw firm 258 conclusions.

260 Conclusions on the relative toxicity of emodin (natural) and quinizarin (synthetic) were 261 generally consistent across the four species tested. The two chemicals had similar toxicity to 262 each other with respect to adult survival and reproduction for three out of four species (Table 263 2). The exceptions to this were effects on adult survival of E. albidus and reproduction of 264 E. fetida. For E. albidus, the apparent increased survival under increasing doses of emodin is 265 clearly erroneous and Figure 2c illustrates negligible effects of the two chemicals. Sensitivity 266 of earthworm reproduction was significantly different for the two chemicals, with 267 reproduction more sensitive to emodin than quinizarin $(p<0.0001)$. This finding was 268 confirmed by the $\mathrm{EC}_{50}$ values of $182( \pm 44) \mathrm{mg} \mathrm{kg}^{-1}$ and $>512 \mathrm{mg} \mathrm{kg}^{-1}$ for emodin and 269 quinizarin respectively (Table 2). 


\section{4. Discussion}

272 This study compared the toxicity of two chemical pairs from natural and synthetic origins to 273 test the hypothesis that "chemicals which are structurally similar will have similar toxic

274 effects". Overall, the experiments produced consistent results which revealed that within the

275 chemical pairs, toxicity to lethal and sub-lethal endpoints was similar for the four invertebrate 276 species tested. The exception to this rule was earthworm reproduction, which showed

277 differential sensitivity to the che micals in both naphthoquinone and anthraquinone pairs. The 278 study also revealed that at the highest concentrations tested naphthoquinones were 279 significantly more toxic than the anthraquinones to survival and reproduction, for three of the 280 four species tested.

281

\subsection{Toxicity measurements}

283 There is very little data available on the toxicity of naphthoquinones and anthraquinones to 284 soil organisms, and there is no information on their toxicity to soil invertebrates. 285 Naphthoquinones, particularly juglone, have been reported to have phytotoxic and anti286 microbial properties (Mahoney et al., 2000; Willis, 2000; Hejl and Koster, 2004), and are 287 toxic to a range of aquatic organisms including invertebrates (Wright et al., 2007). 288 Naphthoquinones have also been tested for their efficacy as control agents for invertebrate 289 crop pests, as they act as growth-disruptors to above-ground invertebrates (Banerjee et al., 290 2001; Lee, 2008).

292 There is a similar paucity of data for anthraquinone effects on soil organisms, although 293 emodin has been shown to possess allelopathic, phytotoxic, anti-microbial and insecticidal 294 properties (Izhaki, 2002; Basu et al., 2005). Toxicity data for anthraquinones tested 
295 specifically on soil invertebrates could not be located, however, insecticidal activity of

296 emodin to mosquito larvae has been demonstrated (Georges et al., 2008). Anthraquinones

297 have also been tested for their efficacy as biocides in controlling aquatic nuisance species in 298 ships' ballast water including aquatic plants and invertebrates. The study concluded that

299 naphthoquinones showed higher toxicity and were toxic to a wider range of organisms than 300 anthraquinones, which echoes the conclusions of this study (Wright et al., 2007). Whilst these

301 findings demonstrate the biological activities of naphthoquinones and anthraquinones, the

302 effect concentrations cannot be compared with the results of this study as they were not

303 conducted in soil, which significantly affects the degree of exposure to which the organisms 304 are subjected.

4.2. Interspecific variation in sensitivity

307 In terms of the relative sensitivity of the four invertebrate species, the predatory mite 308 H. aculeifer was the least sensitive to the two naphthoquinones. Exposure to both juglone and 309 1,4-naphthoquinone resulted in $100 \%$ mortality of collembola, earthworms and enchytraeids 310 at nominal concentrations $=512 \mathrm{mg} \mathrm{kg}^{-1}$, and reproduction was similarly sensitive (Fig 1a-c).

311 In contrast, neither chemical had significant effects on reproduction of predatory mites, and 312 their effect on predatory mite survival did not cause $100 \%$ mortality at any concentration 313 tested (Fig. 1d). Interspecific differences in sensitivity to the anthraquinones were less clear 314 cut than for the naphthoquinones, with conflicting results recorded for the two endpoints.

315 Emodin and quinizarin increased mortality of collembola and predatory mites with increasing 316 concentration, but were of limited toxicity to adult survival of earthworms and enchytraeids 317 (Table 2, Fig. 2). Yet, when reproductive effects were examined, earthworm reproduction 318 was significantly reduced on exposure to emodin. 
The interspecific differences in sensitivity to the two naphthoquinones may be explained by

321 the feeding habits of the four species, and the consequent degree of soil contact which each

322 species is subject to. F. candida, E. albidus and E. fetida all burrow in the soil, and ingest 323 micro-organisms, organic matter, or soil and will therefore ingest the chemical incorporated

324 into the soil. In contrast, $H$. aculeifer is a predatory mite feeding on live collembola prey. Its

325 predominant exposure routes are likely to be through the chemical residue remaining in the 326 collembola prey, and through soil contact via absorption through thin areas of the cuticle, with 327 negligible direct ingestion of the chemicals themselves. This difference may explain their 328 lower sensitivity, but does not explain the differences observed in response to the 329 anthraquinones described above. This theory could only be confirmed by further experiments 330 analysing the uptake of chemicals within the individuals exposed. It must also be noted that 331 the survival of predatory mites in the control and solvent controls was lower than the control 332 survival of the other three species tested. We do not have an explanation for this poor survival 333 rate but it is possible that high mortality in the controls could have affected the overall 334 validity of the test for this species.

336 It was not possible to locate any comparative invertebrate toxicity data for naphthoquinones 337 or anthraquinones. However, there are studies investigating the relative sensitivity of soil 338 invertebrate species to other toxic chemicals. In most cases collembolans were found to be 339 more sensitive than earthworms in terms of survival and reproduction with enchytraeids the 340 least sensitive of the three to cadmium (Bierkens et al., 1998) polycyclic aromatic 341 hydrocarbons (Sverdrup et al., 2002) and antibacterial agents (Jensen et al., 2003). As far as 342 we know there have been no studies comparing the relative sensitivity of predatory mites with 343 other soil invertebrates under individual species tests. However, more complex food web 344 exposures to metal and organic contaminants have generally shown low sensitivity of 
345 H. aculeifer, compared with enchytraeids, but similar sensitivity to collembola (Cortet et al.,

346 2006; Pernin et al., 2006; Scott-Fordsmand et al., 2008). These studies are likely to produce

347 different results to single species tests as species interactions and chemical toxicity to the

348 mites prey will play a role in their sensitivity, in contrast to our test where unlimited prey

349 were supplied.

350

351 Comparison of natural and synthetic chemical pairs

352 The focus of this study was to compare the toxicity of structurally similar compounds.

353 Overall, the toxicity within the chemical pairs was broadly similar for both lethal and sub-

354 lethal endpoints. The exception was earthworm reproduction which was differentially

355 sensitive to both the naphthoquinone and anthraquinone pairs, with the natural toxin emodin

356 and the synthetic toxin 1,4-naphthoquinone being more toxic than their respective analogues.

357

358 For the naphthoquinones, the slight difference in the structures of the two naphthoquinones

359 could be responsible for the difference in toxicity. Quinones, such as 1,4-naphthaquinone, act

360 as redox cyclers creating oxidative stress within the organism. Studies with quinones,

361 including 1,4-naphthaquinone, have shown that the addition of an electron-donating group,

362 such as the hydroxyl group on juglone, makes the quinone a weaker oxidising agent and

363 therefore less toxic (Schultz et al., 1997). Given that the two chemicals appear to affect

364 survival in the same way it would appear that 1,4-naphthaquinone has a specific effect on

365 reproduction which may be caused by the absence of the hydroxy group (Schultz et al., 1997).

367 The higher toxicity of emodin compared with quinizarin, to earthworm reproduction, could

368 also be due to differences in chemical structure, with emodin containing an additional

369 hydroxyl and methyl group. Although this is contrary to published evidence which suggests 
that the presence of additional hydroxy groups on substituted quinones may reduce toxicity

371 (Schultz et al., 1997). In addition, the position of the functional group on a quinone may also

372 affect toxicity. Schultz et al. (1997) reported lower toxicity in methyl- and methoxy-

373 benzoquinones with a 2,5-substitution than those with a 2,6-substitution. These effects were

374 reported to be due to stereo-electronic disturbance in the 2,5-substitution, which may not have

375 been present in the 2,6-substitution. Such effects could be responsible for the lower toxicity of 376 quinizarin. In addition, the presence of the methyl group, as an electron accepting moiety on

377 emodin, may also be responsible for the greater toxicity of this substance.

378

\section{Conclusion}

380 Data generated in this study revealed that natural and synthetic chemicals which were 381 structurally similar, had similar toxic effects on lethal and sub-lethal endpoints for three out of 382 four soil invertebrates tested. This would indicate that data on natural chemicals could be 383 useful as a predictive tool for looking at chemical toxicity to a suite of species. However, the 384 differential effect of the chemicals on earthworm reproduction demonstrates that this 385 approach may not be protective of all species. Differences in toxicity identified in the present 386 study may be related to degree of exposure and/or subtle differences in the mode of toxic 387 action for the chemicals and species tested. It may therefore, be possible to predict some 388 differences by looking at the structures of the compounds to identify functional groups that 389 may infer increased or decreased toxicity in one or other chemical. By developing such 390 techniques it may be possible to use read-across from natural to synthetic chemicals on a 391 wider group of compounds.

\section{Acknowledgements}

394 This work was funded by the American Chemistry Council (grant number EEE-00-05). 
396 Banerjee, S., Magdum, S., Kalena, G.P., Banerji, A., 2001. Insect growth regulatory activity

397 of naturally occurring quinones and their derivatives in Dysdercus koenigii Fabr. (Hem.,

398 Pyrrhocoridae). J. Appl. Entomol. 125, 25-30.

399 Basu, S., Ghosh, A., Hazra, B., 2005. Evaluation of the antibacterial activity of Ventilago

400 madraspatana Gaertn., Rubia cordifolia Linn. and Lantana camara Linn.: Isolation of emodin

401 and physcion as active antibacterial agents. Phytother. Res. 19, 888-894.

402 Bierkens, J., Klein, G., Corbisier, P., Van den Heuvel, R., Verschaeve, L., Weltens, R.,

403 Schoeters, G., 1998. Comparative sensitivity of 20 bioassays for soil quality. Chemosphere

$404 \quad 37,2935-2947$.

405 Cortet, J., Joffre, R., Elmholt, S., Coeurdassier, M., Scheifler, R., Krogh, P.H., 2006.

406 Interspecific relationships among soil invertebrates influence pollutant effects of

407 phenanthrene. Envir. Toxic. Chem. 25, 120-127.

408 DEFRA, 2006. REACH Partial Regulatory Impact Assessment after Common Position.

409 Department for Environment, Food and Rural Affairs, May 2006.

410 ECB, 2004. European Chemical Substances Information System (ESIS) http://ecb.jrc.it/.

411 European Chemicals Bureau, Ispra, Italy.

412 Georges, K., Jayaprakasam, B., Dalavoy, S.S., Nair, M.G., 2008. Pest-managing activities of

413 plant extracts and anthraquinones from Cassia nigricans from Burkina Faso. Bioresource

414 Technol. 99, 2037-2045.

415 Hamers, T., Krogh, P.H., 1997. Predator-prey relationships in a two-species toxicity test

416 system. Ecotox. Envir. Safe. 37, 203-212. 
417 Harborne, J.B., Baxter, H., 1996. Dictionary of Plant Toxins. John Wiley \& Sons, London.

418 Hejl, A.M., Koster, K.L., 2004. Juglone disrupts root plasma membrane $\mathrm{H}^{+}$-ATPase activity 419 and impairs water uptake, root respiration, and growth in soybean (Glycine max) and corn 420 (Zea mays). J. Chem. Ecol. 30, 453-471.

421 ISO, 1999. Soil quality - Inhibition of Reproduction of Collembola (Folsomia candida) by

422 Soil Pollutants. ISO/DIS 11267. International Standardization Organisation, Geneva,

423 Switzerland, pp. 1-16.

424 IUCLID, 2000. IUCLID Chemical Datasheet. European Commission, European Chemicals 425 Bureau.

426 Izhaki, I., 2002. Emodin - a secondary metabolite with multiple ecological functions in higher 427 plants. New Phytol. 155, 205-217.

428 Jensen, J., Krogh, P.H., Sverdrup, L.E., 2003. Effects of the antibacterial agents tiamulin, 429 olanquindox and metronidazole and the anthelmintic ivermectin on the soil invertebrate 430 species Folsomia fimetaria (Collembola) and Enchytraeus crypticus (Enchytraeidae).

431 Chemosphere 50, 437-443.

432 Langenheim, J.H., 1994. Higher-plant terpenoids - a phytocentric overview of their ecological 433 roles. J. Chem. Ecol. 20, 1223-1280.

434 Lee, H.S., 2008. Acaricidal activity and function of mite indicator using plumbagin and its 435 derivatives isolated from Diospyros kaki Thunb. roots (Ebenaceae). J. Microbiol. Biotechn. $436 \quad 18,314-321$.

437 Mahoney, N., Molyneux, R.J., Campbell, B.C., 2000. Regulation of aflatoxin production by 438 naphthoquinones of walnut (Juglans regia). J. Agr. Food Chem. 48, 4418-4421. 
OECD, 2004a. OECD Guidelines For The Testing OfChemicals. Test No. 222: Earthworm

440 Reproduction Test (Eisenia fetida / Eisenia andrei). Organization for Economic Co-operation

441 and Development, Paris, France.

442 OECD, 2004b. OECD Guidelines For The Testing Of Chemicals: Test No. 220: Enchytraeid

443 Reproduction Test. Organization for Economic Co-operation and Development, Paris, France.

444 OECD, 2008. OECD Guidelines For The Testing of Chemicals. Test No. 226: Predatory Mite 445 (Hypoaspis (Geolaelaps) aculeifer) Reproduction Test In Soil. Organization for Economic

446 Co-operation and Development, Paris, France.

447 Pernin, C., Ambrosi, J.P., Cortet, J., Joffre, R., Le Petit, J., Tabone, E., Torre, F., Krogh, P.H., 448 2006. Effects of sewage sludge and copper enrichment on both soil mesofauna community 449 and decomposition of oak leaves (Quercus suber) in a mesocosm. Biol. Fert. Soils 43, 39-50.

450 Schultz, T.W., Sinks, G.D., Cronin, M.T.D., 1997. Quinone-induced toxicity to Tetrahymena: 451 structure-activity relationships. Aquat. Toxicol. 39, 267-278.

452 Scott-Fordsmand, J.J., Maraldo, K., van den Brink, P.J., 2008. The toxicity of copper 453 contaminated soil using a gnotobiotic Soil Multi-species Test System (SMS). Environ. Int. 34, $454 \quad 524-530$.

455 Sorokin, N., 2007. The fate and effects of natural chemicals and their structural analogues in 456 the terrestrial environment. $\mathrm{PhD}$ thesis, School of Biological Sciences. University of Reading, 457 p. 253.

458 Sorokin, N., Whitaker, J. 2008. The impacts of selected natural plant chemicals on terrestrial 459 invertebrates. In: Karlovsky, P. (Ed.) Secondary Metabolites in Soil Ecology, Soil Biology 460 vol. 14, Springer, pp255-268. 
461 Sverdrup, L.E., Krogh, P.H., Nielsen, T., Stenersen, J., 2002. Relative sensitivity of three

462 terrestrial invertebrate tests to polycyclic aromatic compounds. Envir. Toxic. Chem. 21, 1927-

4631933.

464 U.S. Environmental Protection Agency. 2006. Estimation Programs Interface for Windows

465 (EPI Suite). http://www.epa.gov/opptintr/exposure/

466 Willis, R.J., 2000. Juglans spp, juglone and allelopathy. Allelo. J. 7, 1-55.

467 Wright, D.A., Dawson, R., Cutler, S.J., Cutler, H.G., Orano-Dawson, C.E., 2007. Screening

468 of natural product biocides for control of non-indigeno us species. Envir. Technol. 28, 309-

469319.

470

471. 
472 Table 1. Key parameters of the selected natural chemicals and their respective synthetic

473 analogues: Chemical Abstracts Service (CAS) number, molecular weight (MW), predicted

474 water solubility ( $\mathrm{Sw}$ ) and $\log \mathrm{K}_{\mathrm{ow}}$.

\begin{tabular}{|c|c|c|c|c|c|}
\hline Compound & CAS no. & Structure & $\mathrm{MW}(\mathrm{g})$ & $\mathrm{S} w\left(\mathrm{mg} \mathrm{I}^{\mathrm{I}}\right)^{\mathrm{a}}$ & $\log K_{\text {ow }}{ }^{a}$ \\
\hline \multicolumn{6}{|l|}{ Naphthoquinones } \\
\hline \multicolumn{6}{|l|}{ Juglone } \\
\hline (5-hydroxy-1,4- & $481-39-0$ & & 174.16 & 5121 & 1.92 \\
\hline \multicolumn{6}{|l|}{ naphthoquinone) } \\
\hline 1,4-Naphthoquinone & $130-15-4$ & & 158.16 & $2417\left(25^{\circ} \mathrm{C}\right)$ & 1.71 \\
\hline
\end{tabular}

Anthraquinones

Emodin $\left(1,3,8\right.$-trihydroxy-6- 518-82-1 $270.24 \quad 2.04\left(19^{\circ} \mathrm{C}\right) \quad 4.01$

Quinizarin

(1,4-dihydroxy-

anthraquinone)
81-64-1

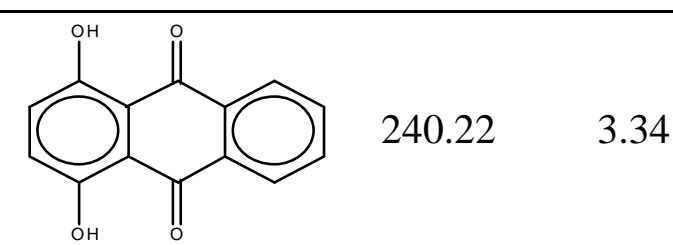


479 Table 2. The effects of exposure to natural and synthetic naphthoquinones and anthraquinones on survival and reproduction of $F$ olsomia

480 candida (28 d exposure), Eisenia fetida (56 d exposure), Enchytraeus albidus (42 d exposure) and Hypoaspis aculeifer (21 d exposure) cultured 481 in OECD artificial soil (OECD, 2004a). Estimated $\mathrm{LC}_{50} / \mathrm{EC}_{50}(\mathrm{SE})$ reported as appropriate. Data were subject to analysis of variance (General 482 linear model, SAS v. 9.1) and are illustrated in Figs. 1-2. Columns labelled p give significance of test for dose-response relationship, or for test of 483 difference in dose-response relationship between sets of chemicals. 


\begin{tabular}{|c|c|c|c|c|c|c|c|c|}
\hline \multirow[t]{2}{*}{ Chemical } & \multicolumn{2}{|c|}{ Folsomia candida } & \multicolumn{2}{|c|}{ Eisenia fetida } & \multicolumn{2}{|c|}{ Enchytraeus albidus } & \multicolumn{2}{|c|}{ Hypoaspis aculeifer } \\
\hline & $\mathrm{p}$ & $\begin{array}{c}\mathrm{LC}_{50} / \mathrm{EC}_{50} \\
(\mathrm{se})\end{array}$ & $\mathrm{p}$ & $\begin{array}{c}\mathrm{LC}_{50} / \mathrm{EC}_{50} \\
(\mathrm{se})\end{array}$ & $\mathrm{p}$ & $\begin{array}{c}\mathrm{LC}_{50} / \mathrm{EC}_{50} \\
(\mathrm{se})\end{array}$ & $\mathrm{p}$ & $\begin{array}{c}\mathrm{LC}_{50} / \mathrm{EC}_{50} \\
(\mathrm{se})\end{array}$ \\
\hline \multicolumn{9}{|l|}{ Adult survival } \\
\hline Juglone & $<0.0001$ & $124(34)$ & $\mathrm{n} / \mathrm{a}$ & $385^{\mathrm{a}}$ & $<0.0001$ & $133(4)$ & 0.001 & $857(192)$ \\
\hline 1,4-Naphthaquinone & $<0.0001$ & $75(15)$ & $\mathrm{n} / \mathrm{a}$ & $385^{\mathrm{a}}$ & $<0.0001$ & $148(14)$ & 0.001 & $606(143)$ \\
\hline Emodin & 0.136 & $404(212)$ & $\mathrm{n} / \mathrm{a}$ & $>512^{\mathrm{b}}$ & 0.035 & $\mathrm{n} / \mathrm{a}$ & 0.149 & $>1024$ \\
\hline Quinizarin & 0.527 & $>512$ & $\mathrm{n} / \mathrm{a}$ & $>512^{b}$ & 0.859 & $>1024$ & 0.225 & $>1024$ \\
\hline Juglone v. 1,4-Naphthoquinone & 0.027 & & $\mathrm{n} / \mathrm{a}$ & & 0.434 & & 0.279 & \\
\hline Emodin v. Quinizarin & 0.590 & & $\mathrm{n} / \mathrm{a}$ & & 0.011 & & 0.700 & \\
\hline All four & $<0.0001$ & & $\mathrm{n} / \mathrm{a}$ & & $<0.0001$ & & 0.053 & \\
\hline \multicolumn{9}{|l|}{ Reproduction } \\
\hline Juglone & $<0.0001$ & $192(37)$ & $<0.0001$ & $239(55)$ & $<0.0001$ & $79(12)$ & 0.055 & $>1024$ \\
\hline 1,4-Naphthaquinone & $<0.0001$ & $110(16)$ & $<0.0001$ & $99(24)$ & $<0.0001$ & $87(17)$ & 0.548 & $>1024$ \\
\hline Emodin & 0.758 & $>512$ & $<0.0001$ & $182(44)$ & 0.259 & $\mathrm{n} / \mathrm{a}$ & 0.614 & $>1024$ \\
\hline Quinizarin & 0.192 & $\mathrm{n} / \mathrm{a}$ & 0.426 & $>512$ & 0.941 & $\mathrm{n} / \mathrm{a}$ & 0.806 & $>1024$ \\
\hline Juglone v. 1,4-Naphthoquinone & 0.074 & & 0.0002 & & 0.854 & & 0.756 & \\
\hline Emodin v. Quinizarin & 0.254 & & $<0.0001$ & & 0.381 & & 0.824 & \\
\hline All four & $<0.0001$ & & $<0.0001$ & & $<0.0001$ & & 0.868 & \\
\hline \multicolumn{9}{|l|}{ Juvenile/ adult ratio } \\
\hline Juglone & 0.922 & & 0.224 & & 0.106 & & 0.987 & \\
\hline 1,4-Naphthaquinone & 0.779 & & 0.003 & & 0.007 & & 0.004 & \\
\hline Emodin & 0.178 & & $<0.0001$ & & 0.327 & & 0.679 & \\
\hline Quinizarin & 0.001 & & 0.427 & & 0.887 & & 0.322 & \\
\hline Juglone v. 1,4-Naphthoquinone & 0.995 & & $<0.0001$ & & 0.132 & & 0.034 & \\
\hline Emodin v. Quinizarin & 0.686 & & $<0.0001$ & & 0.536 & & 0.671 & \\
\hline All four & 0.941 & & $<0.0001$ & & 0.001 & & 0.163 & \\
\hline
\end{tabular}

485 n/a: model did not converge or gave zero or positive dose-response relationship.

$486{ }^{a}$ adult survival was $100 \%$ at concentration $256,0 \%$ at 512, value given is midpoint, model fit and SE ill-defined.

$487{ }^{\mathrm{b}}$ no adult mortality at highest dose 
488 Figure 1. Effects of juglone -- -- and 1,4-naphthoquinone - - (nominal concentrations) 489 on adult survival and reproduction of (a) Folsomia candida (28 d exposure), (b) Eisenia

490 fetida (56 d exposure), (c) Enchytraeus albidus (42 d exposure), (d) Hypoaspis aculeifer (21 d 491 exposure) cultured in standard OECD artificial soil (OECD, 2004a). Data represent the mean $492 \pm$ SE.

493

494 Figure 2. Effects of emodin -- O-- and quinizarin $-\square-$ (nominal concentrations) on adult 495 survival and reproduction of (a) Folsomia candida (28 d exposure), (b) Eisenia fetida (56 d 496 exposure), (c) Enchytraeus albidus (42 d exposure), (d) Hypoaspis aculeifer (21 d exposure) 497 cultured in standard OECD artificial soil (OECD 2004a). Data represent the mean \pm SE. 

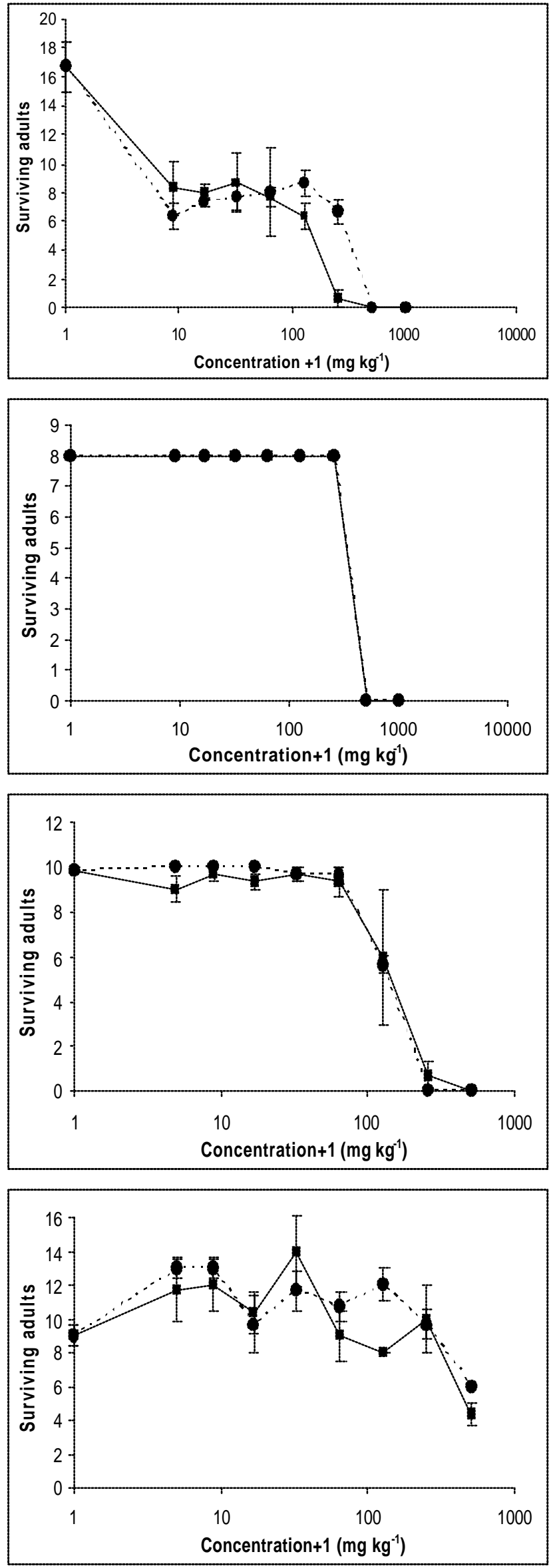
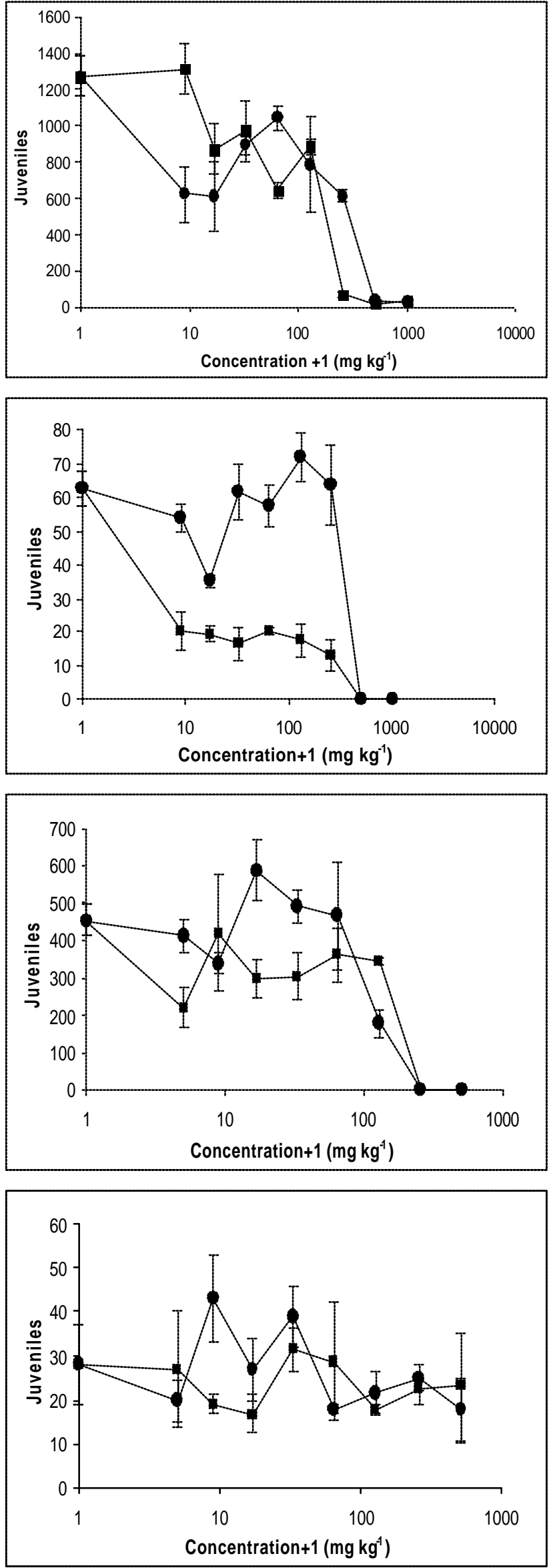

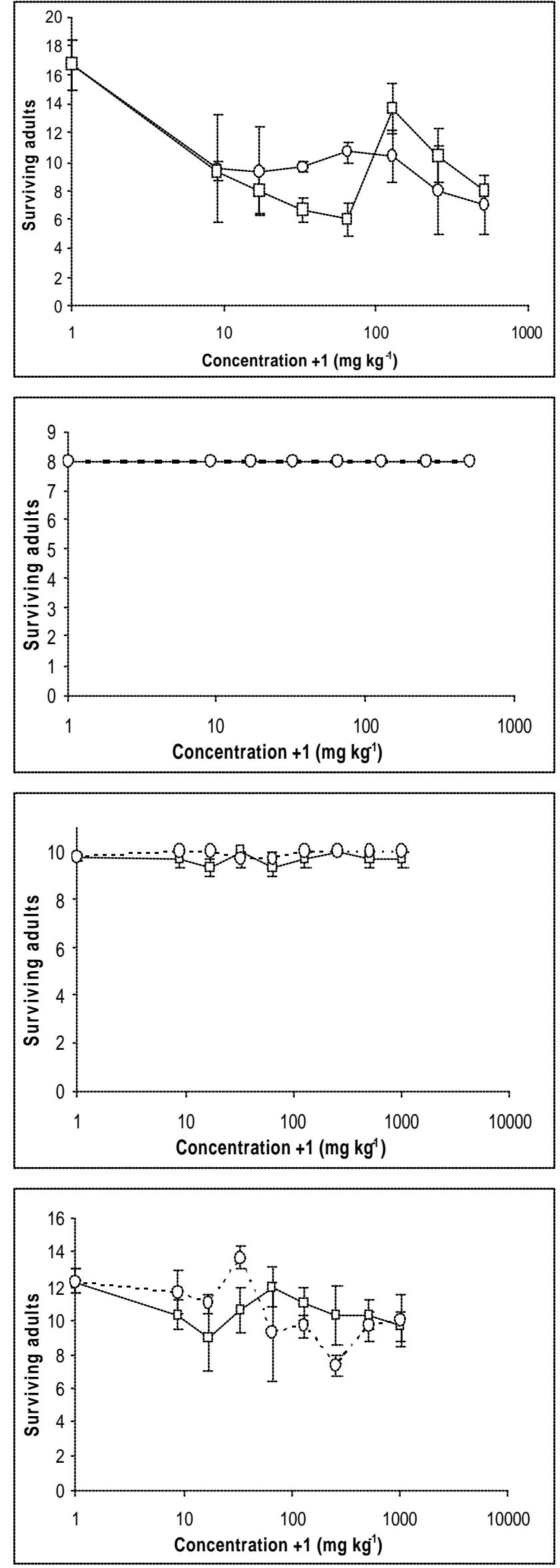
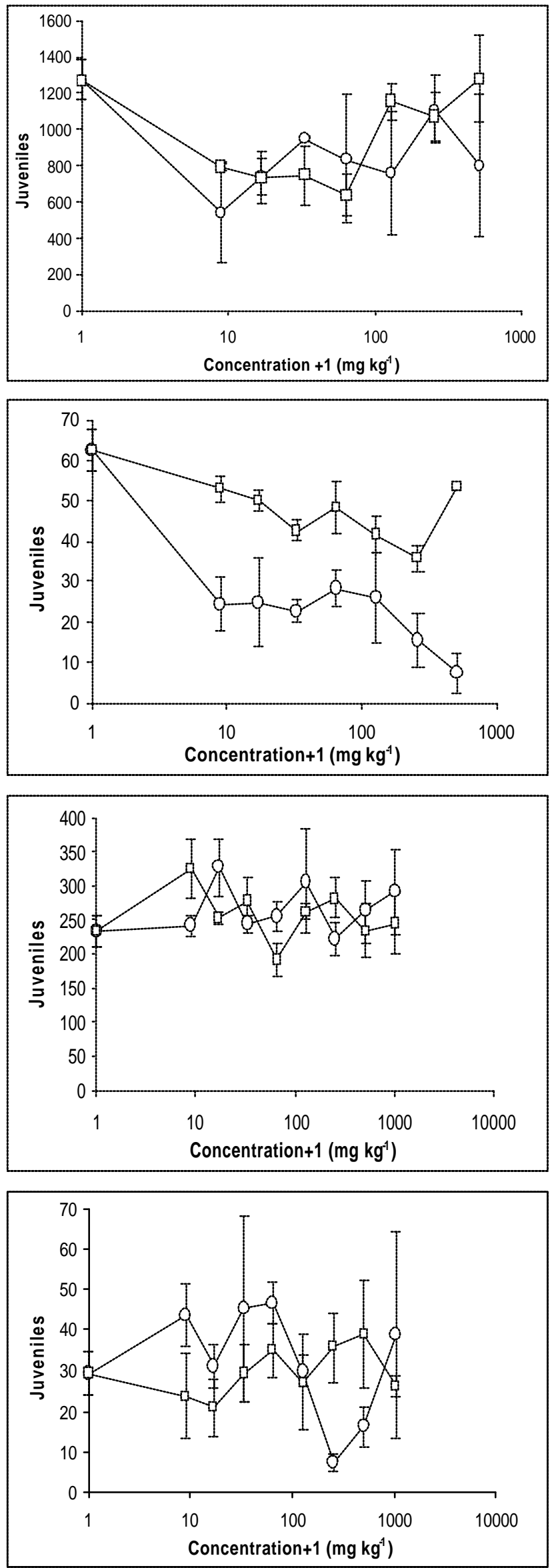